\title{
O sistema cárstico de Vazante - carste em profundidade em metadolomitos do Grupo Vazante - MG
}

\author{
Cristian Bittencourt ${ }^{1}$ \& José Manoel dos Reis Neto ${ }^{2}$
}

\begin{abstract}
Resumo A avançada carstificação dos metadolomitos do Grupo Vazante causa vários problemas geotécnicos e hidrogeológicos na mina subterrânea de zinco da Região de Vazante, MG. Evidências de presença da carstificação em profundidade abaixo do nível de base regional e fora da zona vadosa, incita a busca a modelos espeleogenéticos hipogênicos, que consideram a migração de fluidos ascendente. Este estudo, a partir de diferentes técnicas analíticas, investigou deste a influência de fluidos hidrotermais até os modelos hidrogeológicos conceituais no processo da carstificação.
\end{abstract}

Palavras-chave: Carste Hipogênico, Dolomitização Hidrotermal, Grupo Vazante.

\begin{abstract}
The Vazante karstic system - deep karst in Vazante Group metadolomites - MG. The advanced state of karstification in the metadolomites of the Neoproterozoic Vazante Group cause severe geotechnical and hydrogeological problems in the underground Vazante zinc mine, Minas Gerais State. Evidences of karstification at depths below the regional base level and vadose zone, points to hypogenic espeleogenetic models, that consider the ascendant migration of fluids. In this study different kinds of tools were used to understand the origin of karstification in the area. The investigation started from the influence of hydrothermal fluids on the karstification to the study of hidrogeological conceptual model.
\end{abstract}

Keywords: Hypogenic karst, Hydrothermal Dolomitization, Vazante Group.

INTRODUÇÃO A área objeto do estudo localiza-se na quadrícula limitada pelas coordenadas geográficas $17^{\circ} 54^{\prime}$ e $18^{\circ} 13^{\prime}$ de latitude Sul e $46^{\circ} 45^{\prime}$ e $4705^{\prime}$ de longitude Oeste, Município de Vazante, noroeste do Estado de Minas Gerais, conforme ilustrado na figura 1.

A Mina de Vazante, uma das unidades operacionais da Votorantim Metais Zinco S/A, empresa do grupo Votorantim é a mais importante mina de zinco do país desde a década de 60. Atualmente nesta mina são explotados dois tipos de minérios distintos. O minério secundário, lavrado a céu aberto, é constituído principalmente

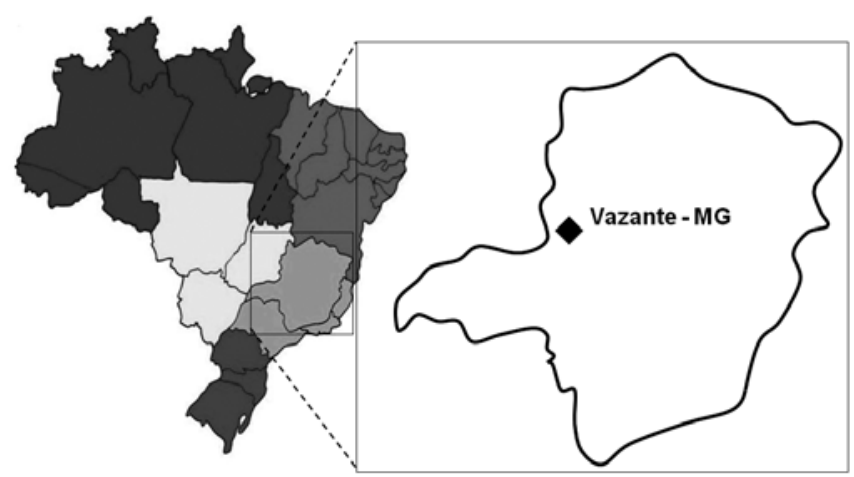

Figura 1 - Mapa de localização do Município de Vazante no Estado de Minas Gerais. por calamina. O minério primário representado por willemita com esfalerita subordinada é explotado por lavra subterrânea e a céu aberto. A mina subterrânea de Vazante está entre as mais complexas do mundo tanto do ponto de vista hidrogeológico quanto geotécnico. Esta complexidade se dá principalmente pelo fato de suas galerias estarem desenvolvidas em rochas carbonáticas do Grupo Vazante, que apresentam elevado estado de carstificação.

A região é constituída por um sistema cárstico complexo e bem desenvolvido, com inúmeras, importantes e interessantes feições representantes do endocarste e do exocarste. O endocarste é representado por dezenas de cavernas incluídas na Província Espeleológica Bambuí (Karmann \& Sanchez 1979). As feições exocársticas mais comuns são as dolinas, sumidouros e nascentes cársticas.

O Sistema Cárstico de Vazante - SCV é considerado complexo em função da sua abrangência e das suas particularidades, tanto do ponto de vista metalogenético como do tamanho das inúmeras cavernas, o que faz a região uma importante área para o estudo e compreensão de modelos espeleogênicos. A grande área de abrangência associada às seguintes peculiaridades faz com que o SCV seja muito interessante para a compreensão da gênese de carstes:

1) presença de inúmeras cavernas/grutas com diferentes localizações geográficas que se encontram 
associadas a importantes zonas de falhas e fraturas, estas relacionadas aos diversos corpos mineralizados em zinco;

2) existência de grutas e cavernas bem desenvolvidas e preservadas que permitem o estudo detalhado das feições e das estruturas presentes em seu interior, bem como as direções de desenvolvimento;

3) presença de poros (vazios) em grandes profundidades e abaixo do nível de base regional;

4) existência da mina subterrânea da Votorantim Metais com uma profundidade de $350 \mathrm{~m}$, o que permite o estudo do comportamento do cárste em perfil desde a superfície;

5) carstificação em grandes profundidade, associada à ocorrência de brechas termobáricas e dolomita hidrotermal;

6) investimento da Votorantim Metais no monitoramento e desenvolvimento de estudos hidrogeológicos e geológicos, o que faz da área uma das regiões cársticas mais estudadas do Brasil.

No interior da mina subterrânea ocorre a presença de feições cársticas com profundidades bem abaixo do nível de base regional, representado na região pelo Rio Santa Catarina. Essas feições são encontradas com até $250 \mathrm{~m}$ abaixo do nível regional, portanto bem fora do que pode ser definida como zona vadosa. A recorrência de feições em profundidade foi também identificada em uma campanha de sondagem de 2004, realizada com o intuito de atingir níveis mais profundos de corpos de minério, nesta oportunidade foram encontradas cavidades a $600 \mathrm{~m}$ de profundidade.

A presença de cavidades (poros) em profundidade não se enquadra aos modelos de carstificação epigênica. Neste modelo a carstificação está associada a processos predominantemente superficiais, no qual a dissolução ocorre a partir da superfície, ocasionados por circulação gravitacional da água, tanto na zona vadosa quanto abaixo dela (Klimchouk 2007).

O presente trabalho visa compreender a gênese do SCV - Sistema Cárstico de Vazante que se encontra desenvolvido nas rochas metadolomíticas do Grupo Vazante. Para isso foram estudados e confrontados diferentes modelos de espeleogênese (epigenéticos e hipogenéticos), a partir das feições de dissolução presentes no interior das cavernas e nos minerais que estão associados à geração de porosidade. A compreensão do modelo e dos processos associados à dissolução pode contribuir no planejamento e na operação de lavra da mina de Vazante, além de servir de comparativo para compreensão de outras regiões cársticas.

MÉTODOS Além do uso de métodos convencionais de geologia de campo para descrição das feições de interesse presentes nas galerias da mina subterrânea e nas cavernas da região, também foram coletadas inúmeras amostras de rocha para estudos em laboratório da química, da isotopia e da cristalografia, tanto das rochas como dos minerais formados nos processos de brechação. Levantamentos foram realizados em quatro cavernas da região com o objetivo de descrever a morfologia dos condutos cársticos em busca de indícios sobre a gênese de formação, usando as características morfológicas sistematizadas por Klimchouk (2007).

Para o estudo mais abrangente da distribuição geográfica do SCV, bem como a sua ocorrência em profundidade, foi realizado a análise morfológica detalhada do sistema cárstico subterrâneo por meio do tratamento estatístico de aproximadamente $300.000 \mathrm{~m}$ de testemunhos de sondagem.

\section{GEOLOGIA, GEOMORFOLOGIA E HIDRO-} GEOLOGIA Do ponto de vista geológico, o Grupo Vazante na área de estudo apresenta quatro unidades definidas por Dardenne (2000): a) Formação Lapa - sequência de filitos intercalados a camadas de quartzitos finos e filitos quartzosos com raras intercalações de metadolomitos; b) Formação Morro do Calcário - constituída por metadolomitos, metadolarenitos, metadolomitos estromatolíticos e brechas; c) Formação Poço Verde - com ardósias e margas intercaladas a camadas de metadolomitos e d) Formação Serra do Garrote constituída de filitos carbonosos e filitos quartzosos.

A zona de falha de Vazante hospeda o corpo mineralizado e separa as formações Morro do Calcário e Poço Verde em dois sistemas aquíferos, denominados de Capa e Lapa, em função da sua relação espacial com o minério de willemita.

Geomorfologicamente a região de Vazante pode ser descrita como uma faixa central de direção geral NE com aproximadamente $60 \mathrm{~km}$ de extensão, com relevo relativamente plano com ocorrência de metadolomitos, que se encontra margeada por um relevo montanhoso representado por metapelitos e metamargas. A faixa central de maior interesse neste estudo é capeada por uma expressiva cobertura coluvionar e aluvionar, com espessura que varia desde poucos metros até uma centena de metros, o que dificulta a identificação e a análise dos processos de carstificação. Este colúvio cobre e mascara um epicarste bastante desenvolvido, onde é comum a identificação de grandes pináculos e paisagens ruiniformes soterradas. Este epicarste foi definido a partir das campanhas de sondagem.

Segundo Frasa (1990), existem na área de estudo cinco sistemas aquíferos distintos, denominados de: a) Manto superior - que corresponde ao epicarste; b) Capa; c) Brecha; d) Lapa Superior e e) Lapa inferior. Para explotação do minério é promovido o rebaixamento do aquífero presente nas imediações da mina, o que 
influencia cada um dos sistemas aquíferos de maneira diferenciada. O perfil da figura 2 ilustra a disposição espacial destes sistemas e o comportamento do lençol freático em cada um.

CARACTERÍSTICAS DAS FEIÇÕES CÁRSTICAS Os estudos e conceitos relacionados aos relevos cársticos consideram dois modelos genéricos de espeleogêneses, denominados de epigênicos e hipogênicos. Nos sistemas epigênicos a dissolução ocorre pela circulação gravitacional da água, tanto na zona vadosa quanto na zona saturada. Cavernas hipogênicas na maioria dos casos são consideradas o oposto das cavernas epigênicas. Klimchouk (2007), define cárste hipogênico como a formação de cavernas por águas que dissolvem por fluxo ascendente, conduzido pela pressão hidrostática ou outra fonte de energia. Ford \& Williams (1989) e Worthington \& Ford (1995) definem cavernas hipogênicas aquelas formadas por águas hidrotermais ou por águas que contêm ácido sulfídrico. Segundo Klimchouk (2007), o conceito de espeleogênese hipogênica está intimamente relacionado à noção de espeleogênese artesiana ou confinada. Estes termos referem-se à condição do aquífero, onde a água subterrânea está sob pressão em uma camada confinada.

Feições Cársticas Rasas em Vazante O SCV faz parte da Província Espeleológica Bambuí, definida por Karmann \& Sanchez (1979), com um total de 41 cavernas conhecidas. Todas as cavernas presentes na região encontram-se na zona vadosa com características de influência de processos epigênicos, como preenchimento com sedimentos recentes e invasão de águas superficiais. Na sua maioria são cavernas secas, com nenhuma evidência de influência de atuação de rios subterrâneos na sua formação direta, como presença de depósitos fluviais em seu interior.

As quatro cavernas estudadas possuem características morfológicas que podem ser atribuídas a processos espeleogenéticos hipogênicos. É comum a observação de feições morfológicas características deste tipo de processo (Klimchouk 2007), como alimentadores

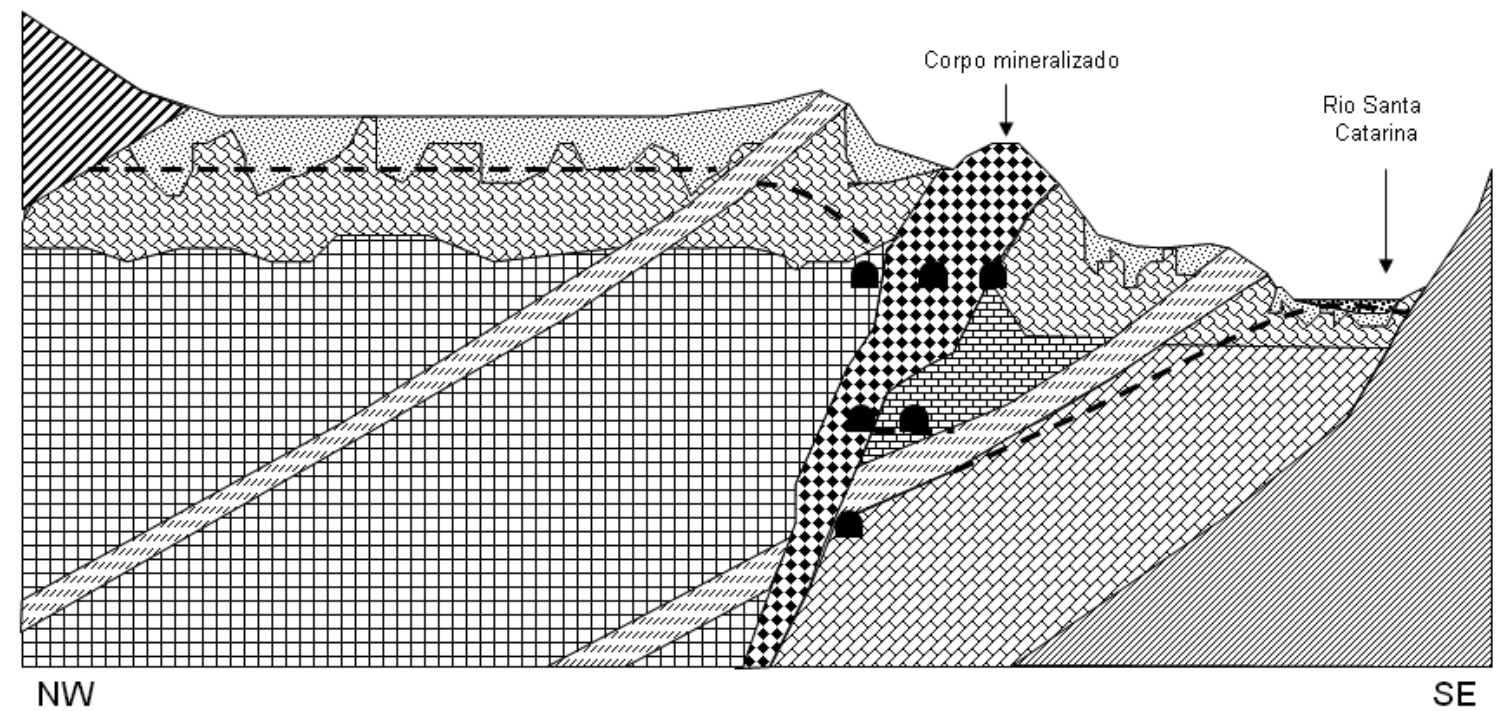

\begin{tabular}{|c|c|c|c|}
\hline Legenda & sistema hidrogeo lógico & Típo & Lito logia \\
\hline इis & Maciço Alterado & Aquífero cárstico & Dolom itos superficiais carstificados \\
\hline 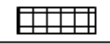 & Capa & Aquífero fissura1/cárstico & Dolomitos rosas \\
\hline 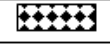 & Brechado & Aquitardo fissural & Dolomitos rosas brechadose mineralizados \\
\hline 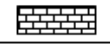 & Lapa Superior & Aquífero fissura1/cárstico & Dolomitos cinzas com intercalações margosas. \\
\hline 3.7. & Aluvião & Aquífero poroso & Pelitos carbonáticos \\
\hline Bays & Lapa Inferior & Aquífero fissura1/cárstico & Dolomitos margosos acinzentados \\
\hline . & Colúvios & Aquífugo & Siltitos argilosos e argilitos \\
\hline QZZ & FormaçãoLapa & Aquífugo & Margas \\
\hline W/W & Formação Serra do Garrote & Aquifugo & Filitos \\
\hline & - - Nível d'água & Galerias & \\
\hline
\end{tabular}

Figura 2 - Sistemas hidrogeológicos existentes no Grupo Vazante na região em estudo. Modificado de Bittencourt et al. (2008). 
(pontos de entrada de fluidos nos sistemas hipogênicos), canais de teto, cúpulas e feições de descarga (Fig. 3).

A Gruta Lapa Nova é a maior cavidade natural subterrânea do Município de Vazante, com seus condutos somando $4.520 \mathrm{~m}$ de extensão (Hydrokarst \& Geoaudax 2011). Possui dois níveis separados por uma camada de metadolomito róseo maciço não carstificado. Além de centenas de pequenos condutos alimentadores espalhados por toda a cavidade, existe um alimentador de maior porte no extremo noroeste da cavidade, distribuindo a água por um grande conduto de direção NW que possui morfologias indicativas de ser um canal escavado por fluxo ascendente. O fluxo neste nível foi preferencialmente de noroeste para sudeste.

Nas grutas Lapa Nova e Lapa Nova II, situadas próxima ao corpo de minério de zinco, os condutos alimentadores principais se encontram na porção mais próxima ao corpo mineralizado. Pelo menos nove cavernas da região de Vazante se acham nesta mesma condição, o que evidencia que suas gêneses foram influenciadas pela presença do corpo de minério e da zona de brechas que se encontra associada.

Feições Cársticas Profundas em Vazante A análise estatística de aproximadamente $300.000 \mathrm{~m}$ de testemunhos de sondagem foi realizada para compreender se existe algum controle da carstificação. Na relação entre a presença de poros/cavidades e o tipo litológico, os dados mostram que $53 \%$ das cavidades ocorrem em associação às brechas termobáricas (próximas ao corpo de minério), $30 \%$ no metadolomito rosa (Capa) e $7 \%$ associados com o metadolomito cinza (Lapa Superior). A análise também mostra que o tamanho das cavidades decresce com a profundidade (Fig. 4). Até uma profundidade de aproximadamente $150 \mathrm{~m}$, cavidades com diâmetros maiores que $15 \mathrm{~m}$ são comuns. Até $300 \mathrm{~m}$ da superfície, o diâmetro das cavidades tende a diminuir, sendo comum serem menores que $10 \mathrm{~m}$. Abaixo de $450 \mathrm{~m}$, o diâmetro das cavidades está restrito a menos de $5 \mathrm{~m}$.

A visualização de cavidades pode ser feita nas diversas galerias da mina subterrânea. Morfologicamente, as cavidades são alongadas, com desenvolvimento predominantemente vertical, controladas principalmente por estruturas de direção noroeste e pela estrutura sedimentar da rocha. São frequentemente observadas feições morfológicas indicativas de fluxo ascendente (Klimchouk 2007), sendo as mais frequentes as cúpulas, tubos verticais e canais de teto (Fig. 5). Também são observadas camadas mais susceptíveis a carstificação e outras menos. Esta característica faz com que as fendas sejam descontínuas, estreitando nas camadas menos carstificáveis (por exemplo filitos e metamargas) e alargando-se lateralmente nas camadas mais favoráveis à dissolução. Feições da descarga de um nível inferior para um superior também são comuns de serem observadas, principalmente em locais de transições entre estratos de diferentes permeabilidades.

\section{A influência do hidrotermalismo sobre a carstificação} em Vazante No SCV foi verificado que tanto a carstificação rasa quanto a profunda possuem grande influência da zona brechada e do corpo mineralizado em willemita. Esta associação permite admitir que o controle da carstificação está coligado às cavidades existentes nas zonas brechadas e mineralizadas. Sendo que o desenvolvimento da porosidade nestas zonas por sua vez pode estar associado a um mesmo processo de formação.

A rocha predominante associada aos metadolomitos são as brechas denominadas de termobáricas compostas por minerais hidrotermais de dolomita e anquerita (Fig. 6). São produtos de um evento de dolomitização associado à circulação de fluidos salinos com temperatura elevada ao longo da zona da Falha de Vazante. Esse evento foi descrito por Monteiro (1997), como infiltração de cimento químico de origem hidrotermal.

As brechas termobáricas têm como características: a) clastos "flutuantes" em meio a matriz; b) feições de reação entre o clasto e o cimento, como substituição dos clastos em suas bordas, causado pela reação com o cimento; c) presença de dolomita hidrotermal (saddle dolomite) e d) assinatura de $\delta^{13} \mathrm{Ce} \delta^{18} \mathrm{O}$ comuns em rochas carbonáticas hidrotermais. A formação de brechas termobáricas é consequência de processos de hidrofraturamento associado a pressões elevadas e temperaturas a partir de $60^{\circ} \mathrm{C}$ até cerca de $250^{\circ} \mathrm{C}$, temperatura de geração da dolomita hidrotermal.

Ford \& Williams (1989) e Worthington \& Ford (1995) definem cavernas hipogênicas como aquelas formadas por águas hidrotermais, porém as observações de campo não mostram nenhuma evidência da gênese do SCV estar diretamente associada ao processo hidrotermal responsável pela formação das brechas termobáricas. No entanto, essas brechas são importantes controles da carstificação por facilitarem a circulação da água em seus poros e cavidades, gerados durante a sua formação. É comum observar a relação entre a dolomita em sela e a presença de cavidades/poros. Quando ocorre a conexão de poros e microporos ocorre a geração de porosidade e permeabilidade e a circulação da água subterrânea (Fig. 7), essa porosidade ao permitir a circulação de fluidos ocasiona a abertura dos poros primários por dissolução, gerando uma porosidade secundária (Fig. 7B), evoluindo para uma protocaverna (Fig. 7C).

GÊNESE DA CARSTIFICAÇÃO As feições morfológicas de dissolução observadas, tanto na mina subterrânea quanto nas quatro cavernas visitadas mostram que as cavidades são produtos de carstificação por fluxo 

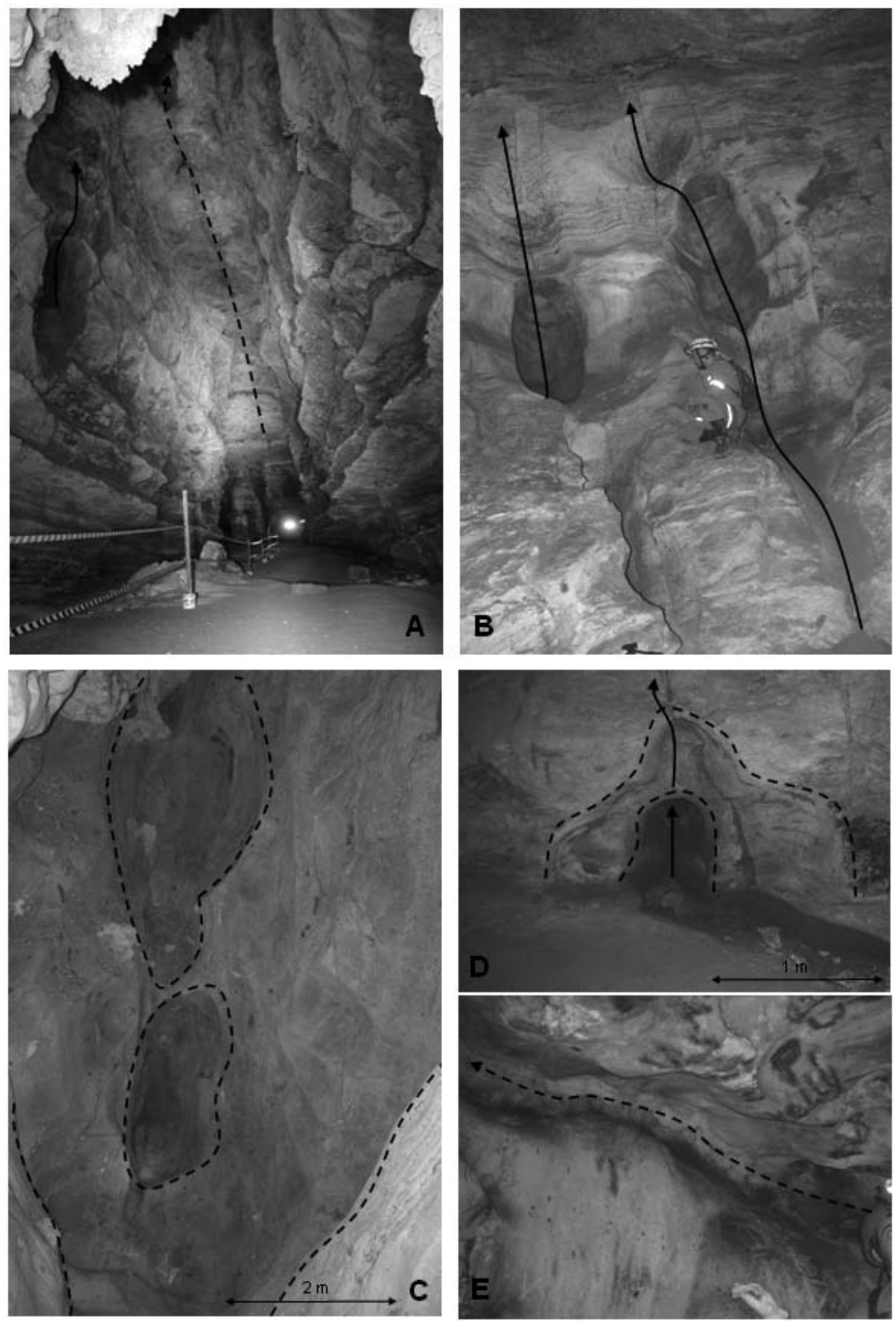

Figura 3 - Feições morfológicas de dissolução por fluxo ascendente descritas na Gruta Lapa Nova. A: Canal de teto (seta tracejada) e canal subindo pela parede (seta cheia). B: Canais subindo pelas paredes da caverna (setas cheias). C: Cúpulas. Fotografia do teto da caverna. D: Alimentador e sequência de cúpulas (linhas tracejadas). E: Espeleotema escavado por fluxo ascendente (canal de teto indicado pela seta tracejada). As setas indicam o antigo sentido de fluxo das águas subterrâneas. 


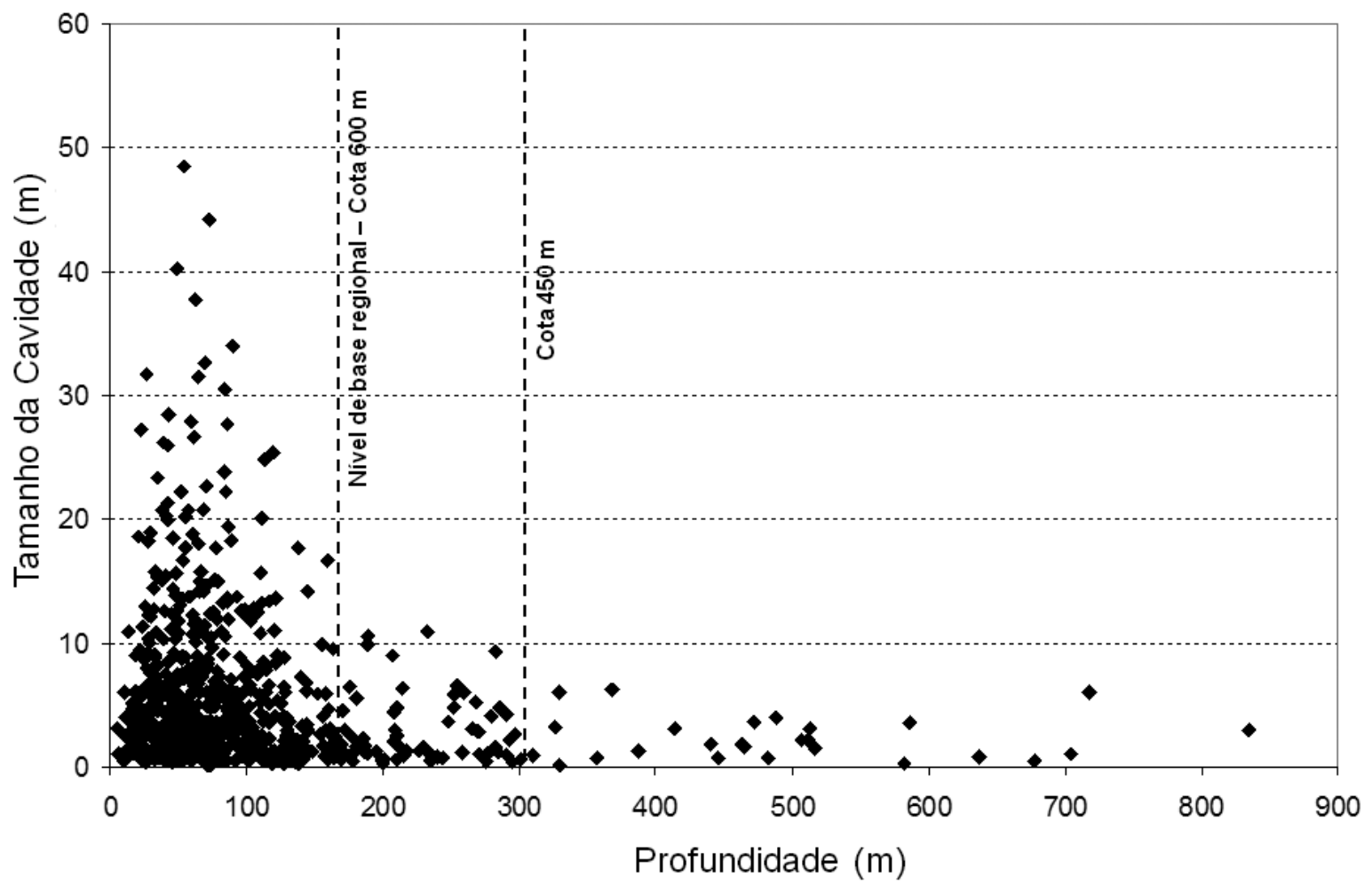

Figura 4 - Gráfico relacionando o tamanho aparente de cavidades versus profundidade de ocorrência.

de água ascendente. Em todas as cavernas analisadas, o fluxo gerador das mesmas foi preferencialmente ascendente, mas quando uma camada propícia à dissolução é atingida, o fluxo se desenvolve preferencialmente de NW para SE (direção do mergulho do acamamento), até que a camada confinante é ultrapassada e um novo nível da caverna começa a se desenvolver. Esta característica é muito interessante de ser observada na Gruta Lapa Nova, onde os condutos se desenvolveram preferencialmente em camadas de metadolomito cinza. A camada que divide os dois níveis da caverna é um metadolomito róseo bandado que não sofreu carstificação.

Nas grutas Lapa Nova e Lapa Nova II, situadas próximas a zona mineralizada, os condutos alimentadores principais se encontram na porção mais próxima ao corpo mineralizado. Pelo menos nove cavernas do SCV estão associadas a esta mesma condição, o que permite aventar que suas gêneses foram influenciadas pelo processo ou pela presença do corpo mineralizado.

Segundo Klimchouk (2007), a condição de confinamento é um elemento essencial da espeleogênese hipogênica, no caso o corpo mineralizado atende este requisito. Esse corpo por estar lenticularizado em profundidade ocasiona o semiconfinamento do aquífero da lapa, quando esse é interrompido (camada confinante), provavelmente ocorre a conexão dos aquíferos da capa e da lapa. A diferença de carga hidráulica entre os dois aquíferos faz com que a água proveniente da capa ascenda pelos poros da brecha termobárica, ocasionando a dissolução e formando os condutos observados atualmente na mina subterrânea. A figura 8 apresenta um perfil esquemático do modelo hipotético apresentado acima.

A ocorrência de processos epigênicos também é uma característica observada na região. Todas as cavernas encontram-se na zona vadosa e apresentam evidências da sobreposição tardia de processos epigênicos na sua formação, como preenchimento com sedimentos recentes e invasão de águas superficiais.

A influência de processos epigênicos e hipogênicos é também ilustrada no modelo apresentado na figura 8. As maiores cavidades ocorrem acima do nível de base regional, na zona vadosa, aonde processos cársticos epigênicos predominam. Entretanto, é necessário atentar que os dados mostram que estas cavidades possuem origem hipogênica e atualmente são relictos na atual condição (zona vadosa). Abaixo desta zona até os $250 \mathrm{~m}$ de profundidade, ocorre a combinação de processos epigênicos e hipogênicos, modelado por IPT 2004, a partir do modelo de circulação freática em aquíferos cársticos (Worthington 1991). Este intervalo de profundidade corresponde ao epicarste descrito por Frasa (1990) como manto alterado. Abaixo da cota $450 \mathrm{~m}$, os fenômenos cársticos são estritamente hipogênicos, as feições são bem representadas pelas protocavernas interceptadas pelas galerias mais profundas da mina subterrânea. À medida que as protocavernas 

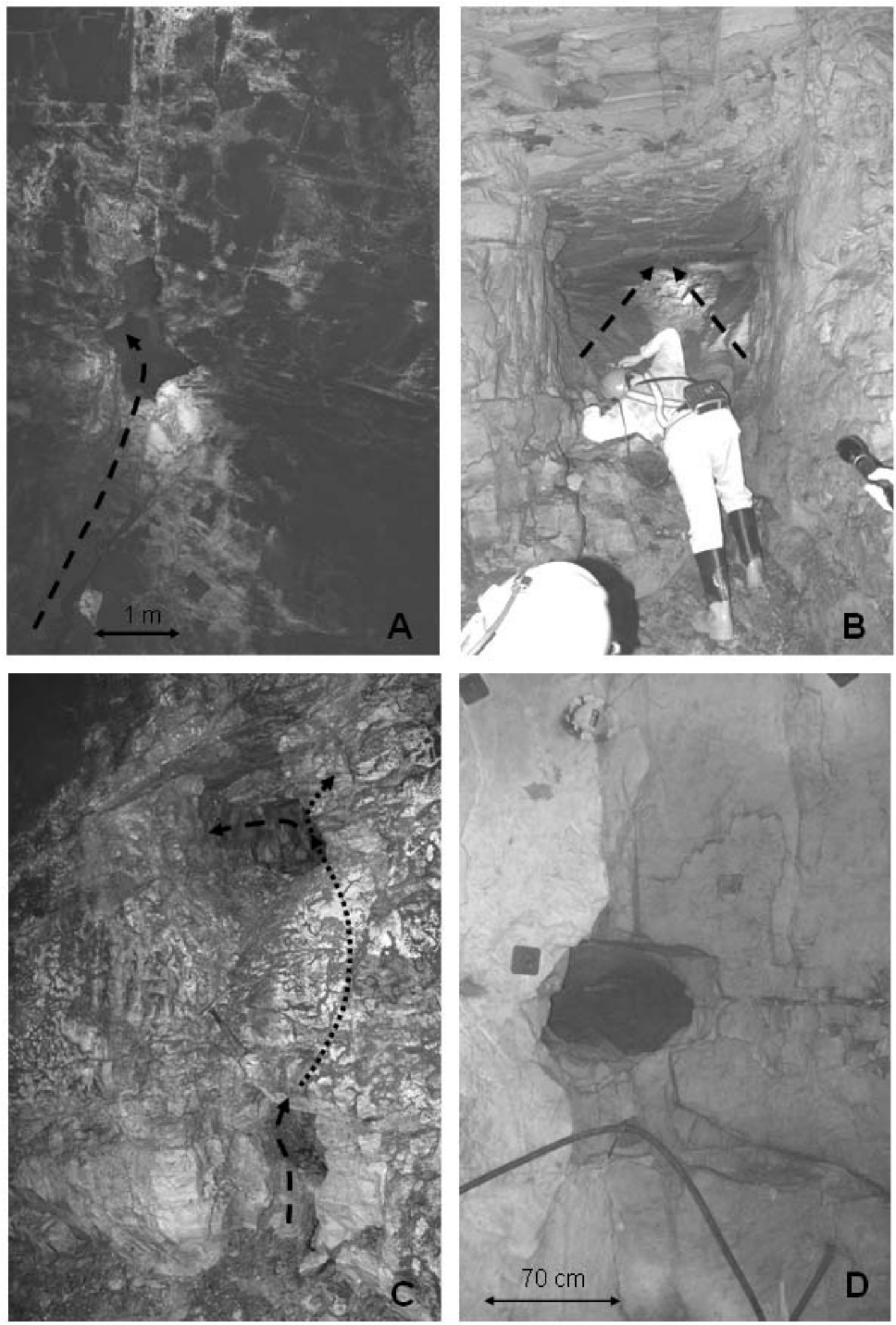

Figura 5 - Exemplos de feições cársticas interceptadas pelas galerias da mina subterrânea. A: Foto de tubo vertical no teto da galeria. A linha tracejada indica um canal de dissolução do teto. B: Foto de feição cárstica cortada na lateral da galeria. A linha tracejada indica a direção do fluxo dentro de uma camada mais susceptível à carstificação com teto de camada margosa menos carstificada. As setas apontam para uma feição de descarga, ponto onde esta camada foi rompida. C: Notar que as carstificações abrem lateralmente quando se desenvolvem em camadas propícias. $D$ : Cúpula representativa de feição de escavação por fluxo ascendente. Locais A, B e C: Travessa da Lumiadeira, nível 500. D: nível 388, Sucuri. 

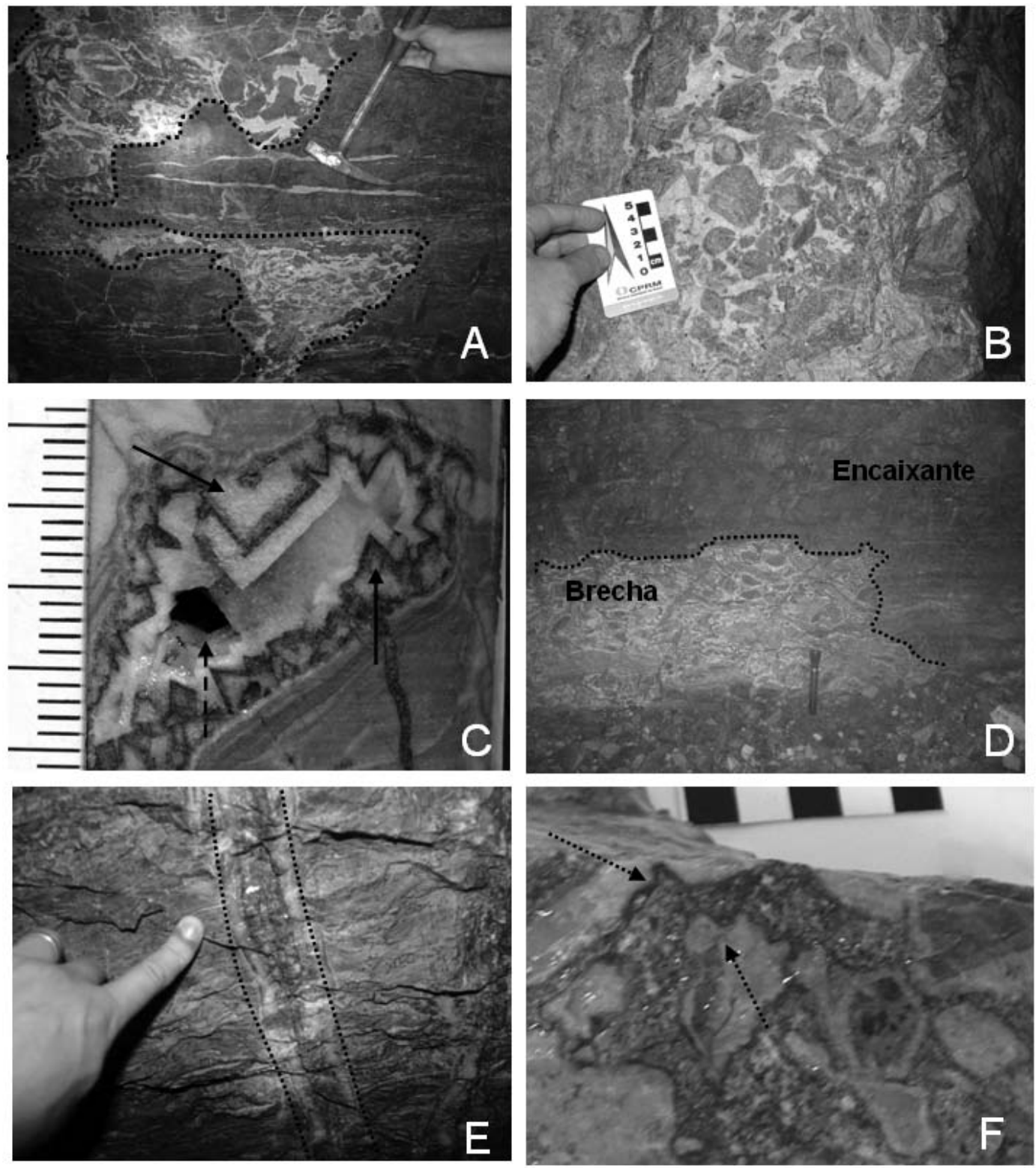

Figura 6 - Afloramentos de brechas localizadas nas galerias da mina subterrânea, compartimento do Sucuri, níveis 345 e 388 (galeria de transporte). Sistema aquífero da Lapa Superior. A: contatos irregulares entre a rocha encaixante e a zona de brecha que apresenta clastos angulosos da própria encaixante; B: fragmentos de dolomitos subarredondados, predominância de cimento composto por dolomita de cor branca; C: Amostra de testemunho de sondagem com vênula preenchida com dolomita em sela (setas cheias) $e$ porosidade primária associada (setas tracejadas); D: contato discordante entre brecha e metadolomito cinza (encaixante); E: Vênula de dolomita com aspecto bandado F: clasto com borda de reação e golfo de corrosão (setas pontilhadas).

ascendem à superfície em função da erosão do relevo, a partir da cota $450 \mathrm{~m}$, a espeleogênese exclusivamente hipogênica, começa a sofrer a ação da circulação freática. Nesta fase ocorre a coexistência de processos cársticos hipogênicos e epigênicos, o que acelera o desenvolvimento das cavidades devido a mistura de águas meteóricas mais agressivas.
As diversas nascentes cársticas descritas por Frasa (1990) são feições associadas a este sistema. Ao alcançar a zona vadosa, as cavernas vão ser expostas em função da sobreposição de processos epigênicos. Nesta fase o carste atinge uma fase matura de desenvolvimento e passa a ser afetado por processos predominantemente epigênicos. A tabela 1 resume as informações apresentadas. 


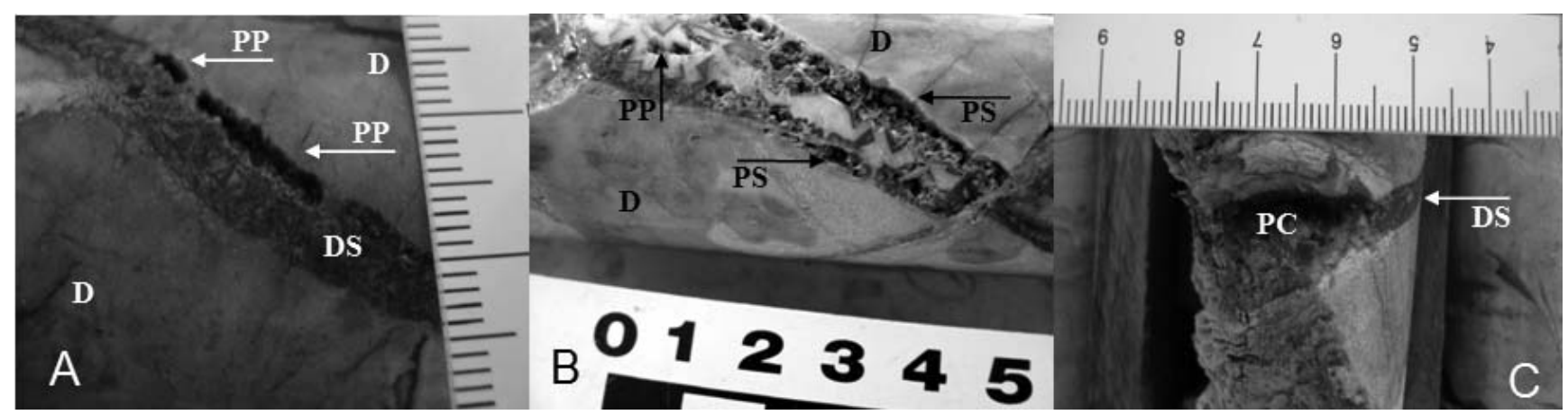

Figura 7 - Feições de porosidade primária e secundária. A: Testemunho de sondagem com vênula preenchida com dolomita em sela (seta cheia) e porosidade primária (setas pontilhadas). B: Testemunho de sondagem com vênula preenchida com dolomita em sela (seta cheia) e porosidade primária (seta pontilhada) sobreposta por porosidade secundária (setas tracejadas). C: Testemunho de sondagem com vênula preenchida com dolomita em sela (seta cheia) associada ao desenvolvimento de uma protocaverna (indicada pelo polígono pontilhado).
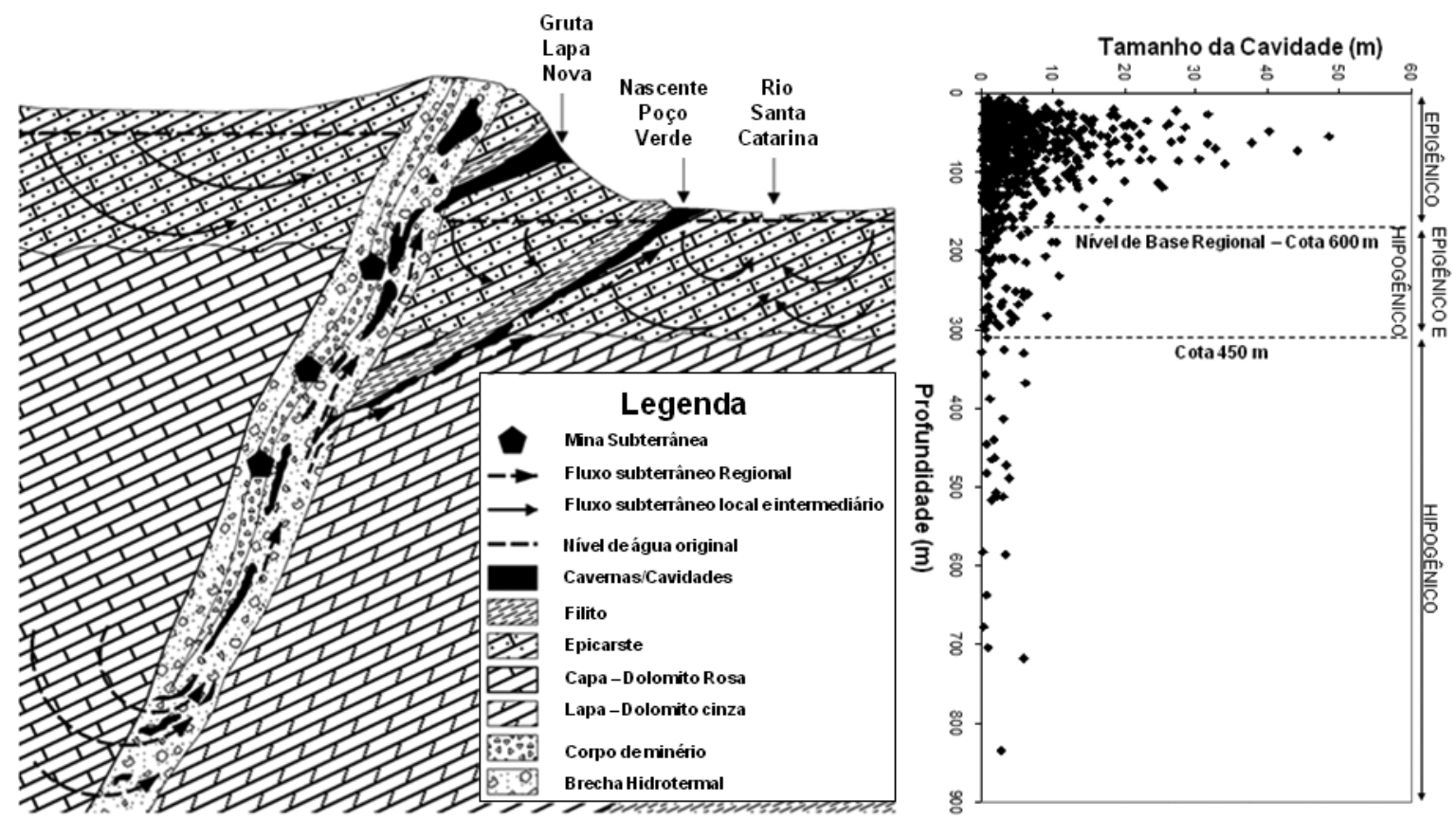

Figura 8 - Modelo hipotético de circulação das águas subterrâneas com fluxo subterrâneo ascendente para o $S C V$.

Tabela 1 - Síntese da SCV nas três faixas altimétricas influenciadas por diferentes sistemas de fluxo e feições cársticas geradas.

\begin{tabular}{|c|c|c|c|c|}
\hline $\begin{array}{c}\text { Faixa altimétrica } \\
(\mathrm{m})\end{array}$ & $\begin{array}{c}\text { Modelo espeleogênico } \\
\text { atuante }\end{array}$ & Tipo de fluxo gerador & $\begin{array}{l}\text { Tamanho das cavidades } \\
\text { (m) }\end{array}$ & $\begin{array}{l}\text { Exemplo de feições } \\
\text { endocársticas }\end{array}$ \\
\hline $\begin{array}{l}\text { Da superfície até a cota } \\
600 \text { m (nível de base) }\end{array}$ & $\begin{array}{l}\text { Exclusivamente } \\
\text { epigênico }\end{array}$ & $\begin{array}{l}\text { Fluxo descendente. } \\
\text { Precipitação }\end{array}$ & $>15$ & $\begin{array}{c}\text { Gruta Lapa Nova, Lapa } \\
\text { da Deusa }\end{array}$ \\
\hline $\begin{array}{l}\text { Da cota } 600 \mathrm{~m} \text { (nível de } \\
\text { base) até a cota } 450 \mathrm{~m}\end{array}$ & $\begin{array}{l}\text { Epigênicos e } \\
\text { hipogênicos }\end{array}$ & $\begin{array}{c}\text { Circulação freática } \\
\text { (IPT 2004, aplicando o } \\
\text { modelo de Worthington } \\
\text { 1991) }\end{array}$ & Entre 15 e 10 & $\begin{array}{c}\text { Nascente do Poço Verde, } \\
\text { Nascente do Sucuri }\end{array}$ \\
\hline Abaixo da cota $450 \mathrm{~m}$ & $\begin{array}{l}\text { Exclusivamente } \\
\text { hipogênico }\end{array}$ & Fluxo ascendente & $<5$ & $\begin{array}{c}\text { Protocavernas } \\
\text { interceptadas pela mina } \\
\text { subterrânea }\end{array}$ \\
\hline
\end{tabular}


CONCLUSÕES O estudo do SCV a partir da morfologia das cavidades e da hidrogeologia local associado a permeabilidade e a porosidade dos diferentes tipo de rochas dolomíticas, permite definir que a geração das cavidades, tanto as acessíveis pela superfície (cavernas) quanto às cavidades interceptadas pela mina subterrânea, foram inicialmente formadas por processos de espeleogênese hipogênica, ou seja, por fluxos ascendentes influenciados pelo semiconfinamento causado pelo corpo de minério de zinco.

Ocorrem três faixas altimétricas importantes para o SCV. A primeira, situada entre a superfície e a cota de $600 \mathrm{~m}$ (nível de base regional), onde atualmente predominam os processos de espeleogênese epigênica, com feições sobrepondo as cavidades formadas por processos hipogênicos. A segunda, situada entre a cota de 600 e $450 \mathrm{~m}$, corresponde a uma zona de início de sobreposição de processos. A terceira zona, situada abaixo da cota $450 \mathrm{~m}$, com feições geradas estritamente por processos espeleogênicos hipogênicos.
O SCV é constituído por diferentes tipos de brechas termobáricas com paragêneses minerais indicadoras de processos hidrotermais. As observações de campo e a análise de testemunhos de sondagem indicam que apesar das cavidades e os poros estarem relacionados principalmente às zonas com brechas termobáricas, suas gêneses não são relacionadas. No entanto, a porosidade proporcionada pelo processo hidrotermal atuou de forma decisiva como agente promotor do fluxo subterrâneo e controla a carstificação atual.

Agradecimentos Ao Grupo Votorantim, ao LAMIR Laboratório de Análise de Minerais e Rochas da UFPR e à PETROBRAS pelo apoio financeiro, fornecimento de informações e dados analíticos para o desenvolvimento deste trabalho. Aos pesquisadores Alexander B. Klimchouk (Ukrainian Institute of Speleology and Karstology) e Augusto S. Auler (Instituto do Carste) pelas discussões em campo que tiveram grande importância para o desenvolvimento deste trabalho.

\section{Referências}

Bittencourt C., De Bessa V., Araújo E.E. 2008. The Vazante underground mine, Brazil - An example of controlled water table drawdown in karstic áreas. In: ASCE, Multidisciplinary Conference on Sinkholes and the Engineering and Environmental Impacts of Karst: Integrating Science and Engineering to Solve Karst Problems, 11, Anais, p. 732-741. doi: $10.1061 / 41003(327) 71$

Dardenne M.A. 2000. The Brasília Fold Belt. In: Cordani U.G., Milani, E.J., Thomaz Filho, A., Campos D.A. (eds.) Tectonic Evolution of South America - 31 ${ }^{\text {st }}$ IGC. Rio de Janeiro, CPRM, p. 231-263.

Ford D.C.\& Williams P.W.(eds.) 1989. Karst Geomorphology and Hydrology. London, Unwin Hyman, 601 p.

Frasa Ingenieros Consultores. 1990. Estudio HidrogeologicoMinero en la Mina Subterránea de Morro da Usina, Vazante, Minas Gerais. Vazante, Votorantim Metais, Relatório Interno, 159 p.

Hydrokarst \& Geoaudax. 2011. Mapeamento Espeleológico das Grutas Lapa Nova e Lapa Nova 2. Vazante, Votorantim Metais, Relatório Interno.

IPT. 2004. Levantamento Geológico-Estrutural nos Entornos da Mina de Zinco da Votorantim Metais - Unidade Vazante, no Município de Vazante, MG, como Subsídio aos Estudos Hidrogeológicos. Vazante, Votorantim Metais, Relatório Interno, 56 p.

Karmann I. \& Sánchez L.E. 1979. Distribuição das Rochas Carbonáticas e Províncias Espeleológicas do Brasil. Espeleo-Tema, 13:105-167.

Klimchouk A.B. (ed.) 2007. Hypogene Speleogenesis: Hydrogeological and Morphogenetic Perspective. Carlsbad, National Cave and Karst Research Institute, $106 \mathrm{p}$.

Monteiro L.V.S. 1997. Contribuição à Gênese das Mineralizações de Zinco da Mina de Vazante, MG. Dissertação de Mestrado, Instituto de Geociências, Universidade de São Paulo, São Paulo, 159 p.

Worthington S.R.H. 1991. Karst Hydrogeology in the Canadian Rocky Mountains. Ph.D. Thesis, McMaster University, Hamilton, 380 p.

Worthington S.R.H. \& Ford D.C. 1995. High Sulfate Concentrations in Limestone Springs: an important factor in conduit iniciation?. Environmental Geology, 25:9-15.

Manuscrito ID 11319 Submetido em 14 de maio de 2008 Aceito em 07 de fevereiro de 2012 